\title{
FAKTOR FAKTOR YANG MEMPENGARUHI KEPUTUSAN KONSUMEN DALAM PEMBELIAN SAYURAN BALE HIDROPONIK SALATIGA
}

\section{FACTORS AFFECTING CONSUMER DECISIONS IN PURCHASING VEGETABLES SALATIGA BALE HYDROPONICS}

\author{
THESYA ANGGREANI TINAMBO, LASMONO TRI SUNARYANTO*
}

Fakultas Pertanian dan Bisnis, Universitas Kristen Satya Wacana

*E-mail: lasmono.jurnal@gmail.com

\begin{abstract}
ABSTRAK
Bale Hidroponik merupakan usaha yang memproduksi sayur-sayuran segar yang diproduksi sendiri dengan sistem hidroponik. Tujuan utama dari penelitian ini adalah mengidentifikasi faktor-faktor yang dapat mempengaruhi keputusan konsumen dalam pembelian sayuran hidroponik dan mengetahui hubungan antara faktor umur, tingkat pendidikan, pendapatan dan pengetahuan dengan keputusan pembelian sayuran merek Bale Hidroponik. Jenis penelitian yang digunakan adalah penelitian deskriptif kuantitatif. Jenis data yang digunakan adalah data primer dan data sekunder. Data primer diperoleh dengan menggunakan metode observasi dengan wawancara melalui panduan kuesioner sedangkan data sekunder digunakan sebagi penguat data primer diperoleh dari pihak Bale Hidroponik atau lembaga yang terkait. Analisis yang digunakan dalam penelitian ini adalah analisis regresi logistik biner, dengan jumlah sampel penelitian sebanyak 55 responden yang diambil menggunakan metode Accidental Sampling. Hasil dari penelitian ini menunjukkan: faktor umur memiliki hubungan yang signifikan dengan keputusan pembelian sayuran merek Bale Hidroponik. Sedangkan faktor tingkat pendidikan, pendapatan dan pengetahuan tidak memiliki hubungan signifikan dengan keputusan pembelian sayuran merek Bale Hidroponik.
\end{abstract}

Kata Kunci: Keputusan Pembelian, Perilaku Konsumen, Bale Hidroponik Salatiga

\section{ABSTRACT}

Hydroponic Bale is a business that produces fresh vegetables which are produced by themselves using a hydroponic system. The main purpose of this research is to identify the factors that can influence consumer decisions in purchasing hydroponic vegetables and to determine the relationship between factors of age, education level, income and knowledge with the purchase decision of vegetables Bale Hydroponic. The type of research used is descriptive quantitative research. The types of data used are primary data and secondary data. The primary data was obtained by using the observation method by interviewing through a questionnaire guide while the secondary data was used as a reinforcement. The analysis used in this study is binary logistic regression analysis, with a total sample of 55 respondents who were taken using themethod Accidental Sampling. The results of this study indicate: the age factor has a significant relationship with the purchase decision of vegetables Bale Hydroponic. While the factors of education level, income and knowledge do not have a significant relationship with the purchase decision of vegetables Bale Hydroponic.

Keywords: Purchase Decision, Consumer Behavior, Bale Hydroponics Salatiga

\section{PENDAHULUAN}

Sayuran merupakan salah satu

komoditas yang berprospek tinggi karena dibutuhkan sehari-hari dan permintaannya cenderung terus meningkat. Saat ini masyarakat mengkonsumsi sayuran setiap saat karena memiliki manfaat bagi kesehatan. Sebagian besar manfaat 
mengkonsumsi sayuran adalah sebagai sumber serat, mineral, dan vitamin untuk tubuh dan kesehatan manusia (Suwandi, 2009). Berbagai cara dan teknologi dalam pertanian telah dikembangkan untuk dapat memproduksi sayuran dan memenuhi permintaan masyarakat.

Salah satu sistem teknologi pertanian yang dikembangkan, khususnya di daerah perkotaan saat ini adalah sistem pertanian hidroponik. Sayuran hidroponik merupakan sayuran yang diproduksi atau ditanam dengan menggunakan air atau media non tanah sebagai tempat hidupnya. Sayuran hidroponik seringkali juga merupakan sayuran organik karena diproduksi dengan tidak menggunakan pestisida.

Menurut Roidah (2014), budidaya sayuran dengan sistem hidroponik memiliki banyak kelebihan yaitu menggunakan teknik penanaman yang baik, perawatan yang mudah, serangan hama mudah dikontrol, hemat dalam pemakaian pupuk dan tenaga kerja yang dibutuhkan tidak banyak serta pertumbuhan sayuran lebih cepat. Budidaya dengan sistem hidroponik juga dapat mengatasi lahan pertanian yang semakin berkurang.

Saat ini masyarakat lebih teliti dalam mengatur pola makan yang bertujuan untuk menjaga kesehatan. Hal ini yang menjadikan sayuran hidroponik menjadi salah satu pilihan masyarakat untuk mengkonsumsi sayuran yang sehat. Dibandingkan dengan sayuran konvensional, sayuran hidroponik memiliki kualitas yang lebih baik. Sayuran hidroponik mengandung banyak mineral dan vitamin yang bermanfaat bagi kesehatan manusia. Hal ini sesuai dengan hasil tes dari Laboratorium Teknologi Tanaman Universitas San Jose California pada tahun 1994 (Anonimous, 2016). Salah satu produsen sayuran hidroponik di Salatiga adalah Bale Hidroponik Salatiga.

Perilaku konsumen adalah suatu tindakan untuk mendapatkan, mengkonsumsi, dan menghabiskan produk dan jasa, termasuk mendasari konsumen dalam membuat keputusan pembelian. Keputusan pembelian merupakan kegiatan individu yang terlibat secara langsung dalam pengambilan keputusan untuk melakukan pembelian produk yang ditawarkan oleh penjual. Keputusan pembelian dapat dipengaruhi oleh faktor umur, pekerjaan, pendapatan, gaya hidup, kepribadian dan konsep diri pembeli yang bersangkutan serta pengetahuan yang terkait dengan perilaku konsumen (Simamora, 2008). 
Berikut beberapa faktor yang berhubungan dengan keputusan pembelian, yang digunakan dalam penelitian ini:

\section{Umur}

Menurut Laitety et al. (2018), umur dibagi atas tiga kelompok yaitu:

a. Umur muda atau belum produktif (0-14 tahun)

b. Umur dewasa atau umur produktif (1564 tahun)

c. Umur tua atau tidak produktif yaitu 65 tahun keatas.

$$
\text { Umur bisa menyebabkan }
$$

kemampuan daya ingat menurun, sehingga dapat mempengaruhi kreatifitas seseorang dalam menerima dan mengembangkan ideide yang kreatif. Selain itu, umur yang lebih muda lebih cepat merespon suatu masalah dan mudah untuk menemukan ide. Pada umur 20-an seseorang biasanya mengalami transformasi dari remaja menjadi dewasa muda. Sehingga pada umur 20-an merupakan waktu yang tepat untuk memulai hidup sehat, dan lebih kreatif (Beverly et al, 2008).

\section{Tingkat Pendidikan}

Tilaar (2002) menyatakan bahwa pendidikan merupakan suatu proses pengenalan terhadap diri sendiri. Dalam pendidikan dapat diperoleh gambaran bahwa ada proses belajar dan pembelajaran, sehingga pada proses pendidikan jelas terjadi pembentukan karakter dan sikap dalam mengubah serta menentukan suatu pilihan.

Pendidikan yang tinggi memudahkan konsumen dalam mempertimbangkan halhal buruk yang akan terjadi, dapat meminimalisir resiko saat mengkonsumsi suatu produk serta lebih kritis terhadap pemilihan produk yang akan dikonsumsi (Budiman, 2014).

\section{Pendapatan}

Menurut Fazrina et al. (2013), jika pendapatan tinggi maka konsumen dapat melakukan kegiatan dan memenuhi kebutuhan yang lebih baik. Hal ini disebabkan karena dana yang dimiliki konsumen cukup. Pendapatan juga dapat mempengaruhi keputusan konsumen untuk membeli. Pendapatan yang tinggi memiliki peluang untuk membeli barang atau jasa yang tinggi serta berpengaruh dalam mengambil keputusan yang berkaitan dengan pemilihan suatu jenis, kualitas maupun harga barang yang hendak mereka konsumsi.

\section{Pengetahuan}

Menurut Engel et al. (1994), pengetahuan merupakan suatu informasi yang dapat disimpan di dalam ingatan seseorang. Pengetahuan konsumen merupakan suatu himpunan dari informasi yang relevan dengan fungsi konsumen di 
dalam pasar. Terdapat tiga bidang umum dalam pengetahuan konsumen yaitu:

a. Pengetahuan produk yang mencakup kesadaran konsumen akan suatu kategori merek produk, ciri produk dan kepercayaan konsumen terhadap suatu produk baik secara umum maupun merek yang spesifik.

b. Pengetahuan pembelian yang mencakup informasi produk yang akan dibeli dan kapan harus terjadi pembelian.

c. Pengetahuan pemakaian mencakup informasi mengenai bagaimana produk dapat digunakan dan apa yang diperlukan agar benar menggunakan produk tersebut.

\section{METODE PENELITIAN}

Jenis penelitian yang digunakan adalah penelitian deskriptif kuantitatif menggunakan data primer dan data sekunder.

Teknik pengambilan sampel menggunakan Accidental Sampling. Accidental Sampling. Dalam penelitian ini jumlah sampel sebanyak 55 responden yang kebetulan bertemu dan melakukan pembelian sayuran Bale Hidroponik.

Teknik pengumpulan data dalam penelitian ini menggunakan teknik observasi, wawancara, kuesioner dan studi pustaka yang berlokasi di swalayan "Ada Baru":

Teknik analisis data yang digunakan untuk pengolahan data penelitian yaitu analisis regresi logistik biner. Menurut Gujarati (2012), model logistik merupakan model yang digunakan untuk memodelkan variabel respon $(\mathrm{Y})$ yang bersifat kategori berdasarkan satu atau lebih variabel predictor $(\mathrm{X})$, baik yang bersifat kategori maupun kontinu.

$\left(\frac{P i}{1-P i}\right)$ Persamaan model logistik yang digunakan:

$\ln =\beta 0+\beta 1 X 1+\beta 2 X 2+\beta 3 X 3+\beta 4 X 4+$

e

Dimana:

$P i=$ Peluang konsumen membeli sayuran hidroponik

$1-P i=$ Peluang konsumen tidak membeli sayuran hidroponik

$\ln =\quad$ Keputusan Konsumen (Membeli $\mathrm{Y}=$ 1, Tidak Membeli $Y=0$ )

$x 1=\quad$ Umur (tahun)

$x 2=$ Tingkat pendidikan (tahun)

$x 3=\quad$ Pendapatan $(\mathrm{Rp} / \mathrm{bln})$

$x 4=$ Pengetahuan

$\mathrm{e}=\quad$ Error

$\beta 0, \beta 1, \beta 2, \beta 3, \beta 4$, adalah Parameter

Kriteria uji analisis regresi logistik biner dalam penelitian ini yaitu: 


\section{Uji Hosmer and Lemeshow}

H0:(1-B) $=0, \mathrm{~B}$ (distribusi frekuensi estimasi/observasi $)=1$. Artinya tidak ada perbedaan antara distribusi obeservasi dengan distribusi frekuensi estimasi, sehingga model dinyatakan layak digunakan. H1: ada perbedaan antara distribusi observasi dengan distribusi frekuensi estimasi.

Sig. > 0,05; tolak H1, terima H0

Sig. $\leq 0,05$; terima H1, tolak H0

\section{Uji Seluruh Model (Uji G)}

$\mathrm{H} 0: \beta 1=\beta 2=\beta 3=\beta 4=0$, dimana tidak ada satupun variabel bebas yang berpengaruh terhadap variabel terikat. $\mathrm{H} 1$ : $\beta 1=\beta 2=\beta 3=\beta 4 \neq 0$, sekurang-kurangnya terdapat satu variabel bebas yang berpengaruh terhadap variabel terikat.

Sig. > 0,05; tolak H1, terima $\mathrm{H} 0$

Sig. $\leq 0,05$; terima $\mathrm{H} 1$, tolak $\mathrm{H} 0$

\section{Uji Wald}

Uji ini untuk menguji signifikansi setiap variabel bebas. $\mathrm{H} 0: \beta \mathrm{j}=0$ untuk suatu $\mathrm{j}$ tertentu; $\mathrm{j}=1,2,3,4,5$..p maka tidak ada pengaruh antara variabel bebas dengan variabel terikat. $\mathrm{H} 1: \beta \mathrm{j} \neq 0$ maka ada pengaruh antara variabel bebas dengan variabel terikat.

$\mathrm{Wj} \leq \chi 2$ atau Sig. $>0,05$; terima H0, tolak H1

$\mathrm{Wj}>\chi 2$ atau Sig. $<0,05$; terima H1, tolak HO

\section{Efek Marginal}

Efek marginal dapat melihat rata-rata perubahan dengan cara menghitung suatu variabel bebas sementara variabel lain dianggap konstan. Untuk model logit, tingkat perubahan probabilitas dari kejadian sebuah peristiwa adalah sebagai berikut:

Efek Marjinal $=\beta . P .(1-\mathrm{P})$

Dimana:

$P=$ probabilitas konsumen membeli sayuran hidroponik

$\beta=$ koefisien dari variabel independent

\section{HASIL DAN PEMBAHASAN}

Faktor-faktor yang mempengaruhi keputusan konsumen dalam pembelian sayuran merek Bale Hidroponik ini menggunakan regresi model logistik biner. Analisis yang digunakan ini bertujuan untuk melihat peluang variabel bebas yaitu umur konsumen, tingkat pendidikan konsumen, pendapatan konsumen dan pengetahuan konsumen apakah memiliki pengaruh atau tidak terhadap variabel terikat yaitu keputusan konsumen dalam membeli sayuran hidroponik (1) dan keputusan konsumen untuk tidak membeli sayuran hidroponik (0). Melalui uji yang dianalisis dengan software SPSS 16.0 maka didapatkan hasil pada Tabel 1. 
Tabel 1. Faktor Faktor yang Mempengaruhi Keputusan Konsumen dalam Pembelian Sayuran Bale Hidroponik

\begin{tabular}{cccc}
\hline Variabel & B & Sig. & $\operatorname{Exp(B)}$ \\
\hline Umur & -.274 & .018 & .760 \\
Tingkat & -.206 & .519 & .814 \\
Pendidikan & .380 & .277 & 1.000 \\
Pendapatan & 19.649 & .999 & $3.424 \mathrm{E} 8$ \\
Pengetahuan & 1.000 & .001 \\
Contant & -6.630 & 1.000 \\
\hline
\end{tabular}

Negelkerke R-square $=0.776$

$\mathrm{G}=38.562(\mathrm{sig}=0,000)$

Chi-square $=4.247(\operatorname{sig}=0.751)$

Persamaan Logit:

Adapun rumus dari metode logit ini adalah: $\ln =\frac{P i}{1-P i}-6,630+0,274 \mathrm{X} 1+0,206 \mathrm{X} 2+0$, $380 \times 3+19,649 \times 4$

Dimana:

$\mathrm{Pi}=$ Peluang konsumen membeli sayuran hidroponik $(\mathrm{Y}=1)$

1-Pi $=$ Peluang konsumen tidak membeli sayuran hidroponik $(\mathrm{Y}=0)$

$\mathrm{Y}=$ Keputusan konsumen

$x 1=$ Umur (tahun)

$x 2=$ Tingkat pendidikan (tahun)

$x 3=$ Pendapatan $(\mathrm{Rp} / \mathrm{bln})$

$x 4=$ Pengetahuan

\section{Uji Hosmer and Lemeshow}

Hasil uji Hosmer Lemeshow Test dapat ditunjukkan pada tabel berikut:

Tabel 2. Hosmer and Lemeshow Test

\begin{tabular}{|c|c|c|c|}
\hline Step & $\begin{array}{c}\text { Chi- } \\
\text { square }\end{array}$ & df & Sig. \\
\hline 1 & 4,247 & 7 & 0,751 \\
\hline
\end{tabular}

dapat dilihat bahwa nilai Chi-square yang diperoleh adalah sebesar 4,247 dengan tingkat signifikansi sebesar 0,751 . Tingkat signifikansi yang diperoleh $>0,05$, sehingga $\mathrm{H} 1$ ditolak dan $\mathrm{H} 0$ diterima. Dengan demikian dapat ditarik kesimpulan bahwa tidak terdapat perbedaan antara distribusi observasi dengan distribusi frekuensi estimasi. Sehingga dapat disimpulkan model logit sesuai untuk digunakan.

\section{Uji Seluruh Variabel (Uji G)}

Hasil uji seluruh variabel dapat ditunjukkan pada Tabel berikut:

Tabel 3. Uji Seluruh Variabel (Uji G)

\begin{tabular}{cccc}
\hline Step 1 & $\begin{array}{c}\text { Chi- } \\
\text { square }\end{array}$ & df & Sig. \\
\hline Model & 38.562 & 4 & .000 \\
\hline Pada & hasil & perhitungan & yang
\end{tabular}
ditampilkan pada Tabel 3 dapat dilihat bahwa nilai $G$ yang diperoleh adalah sebesar 38,562 dengan tingkat signifikansi sebesar 0,000. Tingkat signifikansi yang diperoleh 0,000<0,05. Berdasarkan kriteria pengambilan keputusan yang telah dibuat maka $\mathrm{H} 1$ diterima dan $\mathrm{H} 0$ ditolak. Sehingga dapat disimpulkan bahwa sekurangkurangnya terdapat satu variabel bebas yang berpengaruh terhadap variabel terikat.

\section{Uji Wald}

Pada hasil perhitungan yang ditampilkan pada Tabel 4 dapat dilihat nilai Wald dari masing-masing variabel bebas terhadap variabel terikat sebagai berikut. 
Tabel 4. Uji Wald

\begin{tabular}{ccc}
\hline Variabel & B & Sig. \\
\hline Umur & -.274 & .018 \\
Tingkat & -.206 & .519 \\
Pendidikan & .380 & .277 \\
Pendapatan & 19.649 & .999 \\
Pengetahuan &
\end{tabular}

Nilai Wald antara variabel umur terhadap keputusan yaitu sebesar -0,274 dengan tingkat signifikansi sebesar 0,018. Dari tingkat signifikansi yang diperoleh yakni $0,018<0,05$, dapat disimpulkan bahwa variabel umur berpengaruh terhadap keputusan konsumen.

Nilai Wald antara variabel tingkat pendidikan terhadap keputusan yaitu sebesar -0,206 dengan tingkat signifikansi sebesar 0,519. Dari tingkat signifikansi yang diperoleh yakni 0,519>0,05, dapat disimpulkan bahwa variabel tingkat pendidikan tidak berpengaruh terhadap keputusan konsumen.

Nilai Wald antara variabel pendapatan terhadap keputusan yaitu sebesar 0,380 dengan tingkat signifikansi sebesar 0,277. Dari tingkat signifikansi yang diperoleh yakni $0,277>0,05$, dapat disimpulkan bahwa variabel pendapatan tidak berpengaruh terhadap keputusan konsumen.

Nilai Wald antara variabel pengetahuan konsumen terhadap keputusan yaitu sebesar 19,649 dengan tingkat signifikansi sebesar 0,999. Dari tingkat signifikansi yang diperoleh yakni $0,999>0,05$, dapat disimpulkan bahwa variabel pengetahuan konsumen tidak berpengaruh terhadap keputusan konsumen.

Hasil analisis menunjukkan bahwa variabel umur secara parsial berpengaruh signifikan terhadap keputusan pembelian sayuran merek Bale Hidroponik di Salatiga. Hal ini sejalan dengan teori yang dikatakan oleh Kotler dan Amstrong (2001:207), bahwa umur berpengaruh positif signifikansi terhadap keputusan pembelian karena umur seseorang dapat mengubah barang dan jasa yang akan konsumen beli selama masa hidupnya. Selera konsumen terhadap makanan, pakaian, perabot dan rekreasi berhubungan juga dengan umur. Pembelian suatu barang dan jasa yang akan dilakukan oleh konsumen juga dibentuk oleh tahap daur hidup seseorang. Tahap yang dilalui konsumen sesuai dengan kedewasaannya. Para pemasar sering menentukan sasaran pasarnya dalam bentuk tahap daur hidup konsumen serta mengembangkan produk yang sesuai dengan rencana pemasaran.

Adapun variabel tingkat pendidikan tidak berpengaruh nyata terhadap keputusan konsumen dalam melakukan pembelian sayuran merek Bale Hidroponik. Hal ini disebabkan karena dalam pendidikan formal yang diperoleh konsumen tidak 
mempelajari tentang bagaimana memilih sayuran hidroponik atau sayuran non hidroponik bagi konsumen melainkan diperoleh dari pendidikan non-formal seperti media cetak maupun media elektronik. Hal ini tidak sesuai dengan teori yang dikatakan oleh Muhibbin (2002), bahwa tingkat pendidikan seseorang merupakan salah satu aspek yang terlibat dalam pengambilan suatu keputusan konsumen.

Adapun variabel pendapatan tidak berpengaruh nyata terhadap keputusan konsumen dalam melakukan pembelian sayuran merek Bale Hidroponik. Hal ini disebabkan karena pendapatan konsumen lebih banyak di pakai membeli barang lain untuk di konsumsi dibandingkan dengan membeli sayuran merek Bale Hidroponik.

Adapun variabel pengetahuan juga tidak berpengaruh nyata terhadap keputusan konsumen dalam melakukan pembelian sayuran merek Bale Hidroponik. Hal ini disebabkan karena tahu atau tidaknya konsumen terhadap suatu produk yang akan dibelinya adalah hanya langkah awal untuk memutuskan sesuatu untuk dibeli atau dikonsumsi.

\section{Efek Marginal}

Rumus yang di gunakan dalam metode ini adalah

Efek Marjinal = $\boldsymbol{\beta}$. P. $(1$ - P $)$
Dimana:

$\mathrm{P}=$ probabilitas konsumen membeli sayuran hidroponik

$\beta=$ koefisien dari variabel independen

Efek Marjinal $=\beta . P .(1-P)$

$\mathrm{P} / 1-\mathrm{P}=\operatorname{Exp}(\beta)=0,760$

$\mathrm{P}=(1-\mathrm{P}) 0,760$

$\mathrm{P}=0,760-0,760 \mathrm{P}$

$(1+0,760) \mathrm{P}=0,760$

$\mathrm{P}=\underline{0,760}$

1,760

$\mathrm{P}=0,43$

$$
\begin{aligned}
\frac{\partial \mathrm{P}}{\partial \mathrm{X}} & =\mathrm{P}(1-\mathrm{P}) \\
& =(0,43)(0,57)(-0,274) \\
& =-0,067
\end{aligned}
$$

Nilai marginal efek dari variabel umur adalah sebesar 0,43 artinya setiap peningkatan umur satu tahun, maka akan menurunkan probabilitas peluang keputusan konsumen untuk membeli sayuran merek Bale Hidroponik yang digunakan sebesar $0,067 \%$. Hasil penelitian sesuai dengan hipotesis yang menyatakan bahwa ada pengaruh yang nyata dalam pengalaman membeli terhadap keputusan konsumen untuk membeli sayuran merek Bale Hidroponik.

Berdasarkan hasil wawancara yang telah dilakukan, konsumen yang membeli sayuran hidroponik adalah kalangan umur 20-30 tahun dimana pada umur tersebut disebut sebagai umur orang produktif. 
Menurut Beverly (2008), pada umur 20-an merupakan waktu yang tepat untuk memulai hidup yang lebih sehat dan kreatif. Umur juga bisa menyebabkan kemampuan daya ingat menurun sehingga dapat mempengaruhi kreatifitas dalam menerima dan mengembangkan ide-ide kreatif seseorang.

Adapun faktor tingkat pendidikan, pendapatan dan pengetahuan tidak berpengaruh signifikan dengan keputusan pembelian konsumen dalam melakukan pembelian sayuran merek Bale Hidroponik. Faktor tingkat pendidikan, pendapatan dan pengetahuan tidak berpengaruh disebabkan karena tidak adanya perbedaan signifikan dari konsumen yang menjadi sampel penelitian. Sehingga tidak sesuai dengan hipotesis variabel yang menyatakan bahwa tingkat pendidikan, pendapatan dan pengetahuan mempengaruhi keputusan pembelian konsumen dalam membeli sayuran Bale Hidroponik.

\section{KESIMPULAN DAN SARAN}

\section{Kesimpulan}

Berdasarkan hasil analisis dan pembahasan dalam penelitian tentang hubungan umur, tingkat pendidikan, pendapatan dan pengetahuan dengan keputusan pembelian sayuran Bale
Hidroponik di Salatiga, dapat ditarik kesimpulan sebagai berikut:

1. Umur (X1) memiliki hubungan yang signifikan dan positif terhadap keputusan pembelian sayuran Bale Hidroponik di Salatiga dengan tingkat signifikansi sebesar 0,018.

2. Tingkat Pendidikan (X2) memiliki hubungan yang tidak signifikan terhadap keputusan pembelian sayuran Bale Hidroponik di Salatiga dengan tingkat signifikansi sebesar 0,519.

3. Pendapatan (X3) memiliki hubungan yang tidak signifikan terhadap keputusan pembelian sayuran Bale Hidroponik di Salatiga dengan tingkat signifikansi sebesar 0,277.

4. Pengetahuan (X4) memiliki hubungan yang tidak signifikan terhadap keputusan pembelian sayuran Bale Hidroponik di Salatiga dengan tingkat signifikansi sebesar 0,999.

\section{Saran}

Berdasarkan pembahasan dan kesimpulan di atas, maka dapat direkomendasikan saran penelitian sebagai berikut:

1. Pihak swalayan diharapkan untuk tetap menjaga kualitas produk seperti memberikan ruangan yang baik dan dengan suhu yang terjaga. 
2. Bagi penelitian selanjutnya, diharapkan dapat meneliti faktor-faktor lain yang dapat mempengaruh keputusan pembelian, misalnya faktor budaya dan faktor sosial yang berpengaruh positif dalam penelitian yang telah dilakukan oleh Ishfihana dan Gema (2020).

\section{DAFTAR PUSTAKA}

Anonimous. 2016. Pertanian Organis VSHidroponik.(http://www.bbpple mbang.info/index.php/arsip/artikel/ artikel-pertanian/550pertanianorganik-vs-hidroponik). Diakses 13 Mei 2020.

Beverly, R. Sheila, R. Black and Steven, M. 2008. "Age-related Changes in Creative Thinking." The Journal of Creative Behavior 42.1: 33-59.

Budiman, JA. 2014. Analisis Preferensi Konsumen Terhadap Keputusan Pembelian Madu Di Kota Blitar. Skripsi. Fakultas Peternakan.

Engel, JF. Roger, DB dan Paul, WM. 1994. Perilaku Konsumen Jilid I. Edisi Keenam. FX Bidiyanto, penerjemah. Binarupa Aksar: Jakarta.

Fazrina, R. Marsaulina, I dan Naria, E. 2013. The Correlation of The Characteristics And The Knowledge Of Environmental Health With The Consumers Descision In Purchasing The Organic Vegetables At Carrefour Medan Fair Plaza In Year. Vol. 2 No. 3.

Gurajati, D. 2012. Dasar-dasar Ekonometrika Edisi ke-3. Jakarta: Erlangga
Ishfihana, R dan Gema, WM. 2020. FACTORS AFFECTING DECISION BUYING OF VEGETABLES AND FRUITS ON ONLINE RETAIL. Jurnal Pemikiran Masyarakat Ilmiah Berwawasan Agribisnis. Vol. 6 N.o 1: 275-289

Kotler, P dan Armstrong, G. 2008. Prinsipprinsip Pemasaran. Edisi 12. Jilid 1. (Bob Sabran). Erlangga: Jakarta

Laitety, M. Leunard, K dan Maisie, T. 2018. Werwawan Community Food Consumption Pattern In District Lakor Southwest Maluku Regency. AGRILAN: Jurnal Agribisnis Kepulauan. Vol. 6 No.3. Oktober 2018.

Muhibbin. 2002. Tingkat Pendidikan Individu Merupakan Salah Satu Aspek Yang Terlibat Dalam Suatu pengambilan keputusan. Rajawali Press: Jakarta.

Roidah, IS. 2014. Pemanfaatan Lahan Dengan Menggunakan Sistem Hidroponik. Jurnal Universitas Tulungagung Bonoromo. Vol 1 No. 2: 43-50.

Simamora, B. 2008. Panduan Riset Perilaku Konsumen (3 ed.). (Sukoco, Ed.): PT Gramedia Pustaka Utama: Jakarta

Suwandi. 2009. Menakar Kebutuhan Hara Tanaman Dalam Pengembangan Inovasi Budidaya Sayuran Berkelanjutan. Pengembangan Inovasi Pertanian. Vol. 2 No. 2: 131-147.

Tilaar, HAR. 2002. Manajemen Pendidikan Nasional. Remaja Rosda Karya: Bandung. 